\title{
The Judge-Dependence of Aesthetic and Moral Judgement
}

\author{
Max Kölbel*
}

Received: 14 May 2020 / Accepted: 5 August 2020

\begin{abstract}
This paper develops an account of judge-dependence, conceived of as a generalization of the better known notion of responsedependence. It then solves a number of problems for the view that aesthetic judgements are judge-dependent in this sense. Finally, a parallel case for the judge-dependence of moral judgement is assessed.
\end{abstract}

Keywords: Anti-realism; aesthetic judgement; judge-dependence; moral judgement; Kant; Hume.

In aesthetics and metaethics, as elsewhere, the terms "realism" and "anti-realism" are associated with a number of distinct worries. They may include worries about

(i) whether entities of a certain sort exist;

(ii) whether these entities, if they exist, are somehow basic (explanatorily, reductively, ontologically, or whatever);

(iii) whether judgements involving or concerning these entities are truth-apt; or

(iv) whether such judgements are subject-independent or objective (in some relevant sense).

* University of Vienna

Department of Philosophy, University of Vienna, Universitätsstraße 7, 1010 Wien

$\triangle$ max.koelbel@univie.ac.at

(C) The Author. Journal compilation (C) The Editorial Board, Organon F.

This article is distributed under the terms of the Creative Commons Attribution-NonCommercial 4.0 International Public License (CC BY-NC 4.0). 
In this paper, I shall follow Crispin Wright's (1992) advice to distinguish these worries and then to worry separately. My focus will be on (iv).

There are some reasons why I want to focus on (iv) separately. With the increasing popularity of deflationism about truth the question about truth-aptness, (iii), has become increasingly obsolete - at least as a worry by itself. Or perhaps the worry will now usually not be whether a given topic is truth-apt, but, say, whether truth can be construed as "robust" truth, as provability, knowability or whether it can transcend possible proof and knowledge. The situation is similar with respect to (i): nowadays, before we can decide whether entities of a certain sort exist, we have to specify the sense of existence we have in mind. Or perhaps we have to decide whether we want to be universalists or nihilists about the composition of objects. Question (ii) is also affected by some recent debates: under the heading of "metaphysical grounding" theorists discuss which forms of dependence are ontologically significant.

Thus questions (i) through (iii) are under a kind of foundational dispute: it is not completely clear what is at stake in them. The same goes for question (iv), however, question (iv) seems especially relevant in the case of aesthetic and moral thought, so clarifying and attempting to answer this question seems a good starting point when worrying about the metaphysical status of moral and aesthetic value. This paper will contribute primarily to explaining one conception of subject dependence- "judge-dependence"and explore its prospects in the realm of aesthetic and moral judgements.

In $\S 1$, I shall explain the general idea of what I want to call the "judgedependence" of aesthetic concepts, a generalization of the more familiar phenomenon of response-dependence. In §2, I explain three phenomena that might be thought, and have been thought, to present a problem for the view that aesthetic judgements are judge-dependent. In $\S \S 3$ and 4, I explain how in the case of aesthetic judgements these phenomena can be saved, or explained away, on the judge dependence view. In §5, I shall consider whether a parallel case can be made for moral judgements. Here I shall suggest, that while some of the same motivations are available in the moral case, there are additional features that make the argument much less clear cut. 


\section{Judge-dependence}

It is sometimes said that aesthetic judgements or judgements of taste are distinctively subjective or subject-dependent in the sense of being based on certain types of experience of the person making the judgement. It is debatable whether this characterization by itself really sets aesthetic judgements apart from other, empirical judgements. Why should one think that it is distinctive of aesthetic judgements that they can be made, or are perhaps canonically made, on the basis of certain types of experience? This would seem to be equally true of many empirical judgements that would not normally be regarded as "aesthetic judgements". To say something distinctive about aesthetic judgement, one needs to add specificity. I want to add two more specific points: (i) that the experience is a kind of pleasure or displeasure, and (ii) that the disposition to have these experiences, and on which the correctness of an aesthetic judgement is grounded, often varies from judge to judge.

(i) Kant thought that the experiences in question were experiences of pleasure or displeasure. And he went on to distinguish those aesthetic judgements where the pleasure in question is linked to the satisfaction of some desire (judgements of the agreeable), and those where it is not (judgements of beauty). The important aspect of these Kantian classifications for our purposes will be the observation that the experiences on which certain types of judgement are based are experiences that are intrinsically valuable or desirable (or in the case of displeasure: intrinsically worth avoiding). I will come back to this first point in the next section.

(ii) The second specific point that needs to be added in order to say something distinctive that sets aesthetic judgements apart from other judgements is a certain point about how different judges may be differently disposed to have the experiences in question, and what these differences mean for the correctness of such judgements - a feature I shall call "judgedependence". To explain judge-dependence, I first have to take a step back and say something more generally about judgements and concepts.

The characterization of aesthetic judgements that I am after is a characterization in terms of the distinctive representational content of aesthetic judgements, and this distinctive representational content in turn will 
depend on certain distinctive features of the concepts that are employed in making aesthetic judgements. In general, the representational content of any judgement captures the representational aspects of the judgement. Judgements represent the world as being a certain way and thus help us to conduct ourselves in ways beneficial to us - as long as they represent correctly. (For reasons mentioned in the preamble, I am here using the neutral term "correctly", rather than "truly".) Thus, judgements are not arbitrary or unconstrained, but rather aim at correct representation. For example, a judgement that the shop sells lightbulbs is incorrect if the shop does not sell lightbulbs. There is, thus, a reason to avoid making that judgement unless the shop does sell lightbulbs. There may be judgements that are correct even if the shop does not sell lightbulbs. But they will not be judgements that the shop sells lightbulbs - they will not be judgements with that particular representational content.

In my view, the content of a judgement, together with the way things are, does not always determine whether the judgement is correct. Sometimes, it depends on who is making the judgement, and when. ${ }^{1}$ For example, I want to allow the content that it is Tuesday to be a content that it is correct to believe only on Tuesdays; and the content that one is a philosopher to be correctly believed only when the believer him or herself is a philosopher. I even want to allow a content that it is only correct for David Hume to believe: the content that one is David Hume - a content famously believed in error by Heimson (cf. Lewis 1979a). To be sure, some contents do not exhibit this variability, namely those that have been called "boring" or "portable" (respectively by Andy Egan [2007] and myself [2013, 2014]). If anyone at any time believes such a portable content and does so correctly (or incorrectly), then anyone else who believes the same content at any other time will also do so correctly (incorrectly). For example, the content that a particular shop sells light bulbs in July 2020 is such a portable or boring content.

In the current context it is not important whether we allow such centered or de se contents of representation, or whether all contents must be portable. I want what I say about aesthetic and moral judgements to be

1 In other words, I want to construe representational contents in general as "centered" or "perspectival" contents, see e.g. (Egan 2007, 2012; and Kölbel 2015). 
neutral with respect to the question of whether we allow centered contents. Whenever I say that there is a common content that it is correct to believe by some at some time, and not correct to believe by others or at other times, those who stipulate that all contents are portable (e.g. Frege) will say that there are as many distinct contents of judgement as there are different thinker-time pairs with which correctness can vary. Thus, while I could articulate what I want to say by saying that the contents of aesthetic judgement are typically judge-dependent or non-portable, I shall attempt to find a more ecumenical formulation. The ecumenical formulation focusses on distinctively aesthetic and moral concepts, i.e. on the constituents of such contents, and it thus bypasses the mentioned issues about contents in general.

The content of a particular judgement (and the corresponding conditions under which it is correct to make a judgement with that content) depends on the concepts involved, i.e. the concepts that constitute the judgement's content, which are the concepts employed by the judge in making that judgement. There may be various reasons why it is interesting to say that the contents of judgements are in some sense constituted or determined by concepts. ${ }^{2}$ In the current context, the main reason is that I want to say that aesthetic judgements are judge-dependent because they involve judge-dependent concepts.

Just as judgements are correct depending on their content (and perhaps on who judged the content and when), concepts can be correctly or incorrectly applied to things. Thus, the concept lightbulb is correctly applied to all, and only to lightbulbs. Thinkers who are competent with the concept of a lightbulb have the disposition to apply the concept all and only to lightbulbs, at least when conditions are good. (The exact correlation between competence and correctness of judgement, including the specification

2 Amongst them a desire to explain the large repertoire of potential contents of judgement that are available to individual thinkers, and a desire to explain how different thinkers manage to make judgements with similar or identical content in such a large range of cases, thus being well positioned to communicate their judgements to one another. In other words, the compositional structure of contents is hoped to mirror the structure of individuals' competences as well as the similarity of the competences of individuals in a group. 
of "good conditions," is a complicated issue, which I leave aside here.) Now, some concepts, like that of a lightbulb, are such that their range of correct application is the same for everyone at every time. Other concepts, like that of here, yesterday or one's own uncle are not: the range of things to which these concepts are correctly applicable depends on where, when or by whom they are applied. Those who, under good conditions, do not apply the concept here only to the place where they are, are not competent with the concept. Those who, under good conditions, apply the concept one's own uncle to things other than their own uncle thereby show their incompetence with the concept. ${ }^{3}$

I am stressing the connection between the range of correct application of a concept (for a judge at a time) and the tendency of a competent speaker to apply the concept all and only to things in that range when conditions for judgement are good. I am doing this because we can use this connection - within dialectical limits - when trying to show what the range of correct application of a given concept is. We can do so by observing what kind of behaviour, i.e. what kind of application of the concept, would count as a sign of incompetence with the concept.

In particular, I want to argue that aesthetic concepts impose conditions on their range of correct application that concern the response the judge must be disposed to have to things in that range. Thus, the concept of beauty (or ugliness) can be correctly applied by a thinker to an object if and only if that thinker is disposed, under good conditions, to respond to that object with a certain kind of pleasure (or displeasure). Kant would say: disinterested (dis)pleasure, i.e. (dis)pleasure that does not come from the (lack of) satisfaction of some bodily desire, such as hunger, thirst or a sexual urge. I am not sure whether Kant's point about disinterested pleasure correctly marks the narrowly aesthetic (the beautiful) from the agreeable or merely pleasant or nice. But I do think it is a correct observation that those who apply the concept of beauty to objects that fail to cause a certain

3 It may be worth clarifying that when I am speaking about concept applications, I am speaking about simple judgments in which the concept is applied to an object (i.e. not, for example, applications that occur within a disjunctive judgement. Since my topic is judgement and not linguistic performances, there is no issue of insincere or non-literal applications of concepts. 
pleasurable experience in them, even when the conditions for concept application are good, thereby manifest incompetence with the concept of beauty or ugliness. ${ }^{4}$

There are many concepts that require for their correct application that the judge be disposed to respond in a certain way. I have already mentioned concepts like agreeable, pleasant, nice, which are linked to pleasant experiences of different kinds. But there are many others that suggest themselves: attractive, funny, disgusting, seems $F$ (for variable $F$ ), soporific, thrilling, horrific, great, fantastic, etc. I believe that all (or most) of these concepts have conditions of correct application that follow roughly the following schema:

(JD) For all subjects $s$ and all objects $o$ : it is correct for $s$ to apply $\mathrm{C}$ to $o$ if and only if $s$ is disposed to have experiential response $\mathrm{R}$ to $o$ under favourable conditions.

4 There are some niceties here in specifying the disposition. Thus, one may ask whether a blind person cannot correctly apply the concept of beauty to a (visual) painting, because the painting does not cause the relevant experience in the blind person, not even under favourable conditions. There are various ways of dealing with such cases. One possibility is to say that the blind person never is in favourable conditions, thus can still have the disposition. But if we said that he or she has the disposition vacuously, then we'd also be forced to say that they have the disposition to respond with a certain displeasure under favourable conditions. Thus, it would be correct for that person to judge that the object is beautiful, and also that it is ugly. Another possibility is to say that the blind person is indeed partially incompetent with the concept, at least when visual beauty is concerned. Such a view would seem to have to decide whether there is such a thing as a blind person judging correctly that the painting is beautiful, and if so, on whose response to the painting this depends - or are these uses some kind of "inverted comma uses," which do not manifest employment of the concept, but rather a meta-reflection on how it is correct to apply it?

Another possible difficulty is that it may be claimed that some forms of beauty do not cause pleasure or a pleasurable experience. I am inclined to respond that in so far as this is so, we are talking about an extended concept of beauty that may or may not be culturally or historically related to beauty in the core sense I have tried to characterize. 
If we instantiate the schema for $\mathrm{C}=$ the concept of beauty, we should put something like "aesthetic appreciation" as the response $\mathrm{R}$. If $\mathrm{C}=$ the concept of funniness, then the response should be amusement. If $\mathrm{C}=$ the concept of seeming large, then the response should be an inclination (in the absence of evidence to the contrary) to believe that $o$ is large. If $\mathrm{C}=$ the concept of being great (or fantastic), the response should be enthusiasm.

Evidence for these suggested conditions of correct application is in each case the observation that if someone applies concept $\mathrm{C}$ to objects that do not cause response $\mathrm{R}$ in him or her, even under favourable conditions, then this is an indication that this person is not fully competent with concept $\mathrm{C}$. It may be difficult or controversial to decide in a specific case what the conditions of correct application of a given concept are. Furthermore, it may be controversial whether concepts of this sort correspond to properties, i.e. properties that have corresponding application conditions. However, it ought not to be controversial, that there could be concepts of this sortthat there is nothing incoherent about such concepts per se. Let us call such concepts "judge-dependent".

The range of correct application of a concept need not vary from judge to judge, or from time to time just because the concept is judge-dependent (i.e. just because it conforms to schema (JD)). For example, if the potential judges all happen to be similar in their relevant dispositions to respond under favourable conditions, then that would prevent any divergences in ranges of correct application. Arguably, colour concepts, such as the concept of being red, instantiate schema (JD). Thus failure to apply the concept of redness all and only to those things that cause a certain characteristic experiential response in one, ${ }^{5}$ when conditions are favourable, will be taken to indicate incompetence. ${ }^{6}$ So colour concepts would appear to be a special

5 NB: if we do not want to assume the possibility of making interpersonal comparisons of subjective experiential states, we may not be able to specify the characteristic experiential response in intrinsic terms but may need a relational specification.

${ }_{6}$ As in the case of the concept of beauty, there is a good question of what one should say about those who are constitutionally unable to have the relevant response, but who nevertheless arguably use the concept - a blind person may apply the concept of redness. Many are tempted to say that visual detection of colour is somehow 
case of judge-dependence. However, I would argue that the relevant response $\mathrm{R}$ is here specifiable only in ways that makes sure that the ranges of correct application of different judges at different times do not only happen to coincide, but that they must coincide as a matter of conceptual necessity. ${ }^{7}$ For example, on this view it would be a conceptual truth that if different competent judges are in favourable conditions, the objects to which they will apply the concept of redness will be (roughly) the same. Colour concepts are judge-dependent, but at the same time they are objective: correct application will not depend on who is applying the concept to a given case or when. ${ }^{8}$

Aesthetic concepts, however, do not seem to exhibit judge-dependence in the special way in which colour concepts do: the ranges of objects to

essential to the possession of colour concepts, so that blind people do not have full competence with colour concepts. Another way out would be to allow that under "favourable conditions" blind people would after all have the experiences in question. They are simply never in favourable conditions.

Another problematic aspect is that it may be difficult to identify the response in question. If we say that it is the type of experience brought about by red objects under favourable conditions, then the explanation is blatantly circular. Moreover, it has been argued that there could be systematic qualia-inversion, so that the way one person experiences red objects is the way another person experiences green ones. If colour-qualia inversion is indeed possible, then I tend to think that the type of response mentioned in the relevant instance of (JD) cannot be specified in an intrinsic way, but rather has to be specified, for example, with reference to a list of paradigm red things or with reference to the concept-using practice. In the latter case, $\mathrm{R}=$ the type of visual experience brought about under good conditions by those objects that are classified as "red" in the community in question. Systematic inversion of experiences specified in this way within the community in question is not a coherent possibility. However, inversion of experiences characterized in another, perhaps intrinsic or phenomenological way, would be.

7 For example, $\mathrm{R}$ could be specified as the colour experience caused by ... [here follows a list of paradigm red things] under favourable conditions. This leaves open the possibility that there are phenomenal differences between individuals, see last footnote. Human physiology will ensure that the phenomenology is relatively constant in the same individual over time and under favourable conditions.

8 I am simplifying somewhat by ignoring certain subtle variations, with for example sex or age, in the application conditions of colour terms in certain contexts. 
which judges are disposed to respond with aesthetic appreciation under favourable conditions will vary from judge to judge. The variation is quite regular, and it is well-known to exist. In my view, such variation is not taken to show that some judges are less competent, or that the conditions under which some are operating, are not favourable. Thus, aesthetic concepts, such as the concept of beauty, do not prescribe at the conceptual level that ranges of correct application must coincide between judges.

I realize that this last claim may be controversial, especially for the paradigmatic aesthetic concepts such as beauty and ugliness. It will be one of the tasks of $\S 4$ to explain away some of the phenomena that make it appear controversial. For the moment, however, let us settle for the claim that at least many of the judge-dependent concepts mentioned on the last page (e.g. agreeable, pleasant, attractive, funny, disgusting) are judge-dependent in such a way that the ranges of correct application of these concepts can vary from judge to judge or time to time.

Let me mention, finally, a kind of concept that may easily be confused with a judge-dependent concept. Some (at least possible) concepts depend for their correct application not on the response the judge would have under favourable conditions, but rather on the response an ideal judge would have under favourable conditions. The conditions of correct application of these concepts can be articulated like this:

(IJ) For all subjects $s$ and all objects $o$ : it is correct for $s$ to apply $\mathrm{C}$ to $o$ if and only if an ideal judge would be disposed to have experiential response $\mathrm{R}$ to $o$ under favourable conditions.

One difference one notes immediately is that concepts instantiating schema (IJ) will not be judge-dependent, because it no longer depends on a feature of a judge, whether it is correct for that judge to apply the concept. Rather, it depends on a feature of the ideal judge. This means, on the face of it, that (IJ)-type concepts are not judge-dependent. ${ }^{9}$

Another important difference between schema (IJ) and (JD) is that the link with rational motivation that arises if response $\mathrm{R}$ is something intrinsically desirable, is removed. If an object causes a pleasurable experience in

9 There is a way in which (IJ)-type concepts may nevertheless be judge-dependent, and this is if it depends on the judge what an ideal judge would be like. 
me under favourable conditions, then this will give me some reason to prefer to encounter that object rather than others at least when conditions are likely to be favourable. If the disposition is not my own, but that of an ideal judge, then I no longer have that reason - unless perhaps I believe that I am similar to the ideal judge in the relevant respects, or I have reason to have preferences similar to those of an ideal judge. In any case, the reason would no longer be directly entailed by my judgement, but rather depend on further beliefs or preferences.

The concept of beauty, and perhaps other more narrowly aesthetic concepts, may appear to some to be of the (IJ) type. Remarks like: "This may be beautiful, but I don't appreciate it." or "I prefer the one that is less beautiful.", may suggest this. Moreover, we often have strong views about what sense of taste one ought to have, aesthetic apreciation has an important social role. This too may promote the impression that aesthetic concepts are of the (IJ) variety (more on this below).

Let me summarise, then, the results that I want to take from this section: aesthetic concepts are a kind of judge-dependent concept where the response in question is an experience of pleasure or displeasure of some sort. Moreover, judges regularly vary in their dispositions to have these experiences in response to objects, and as a result the range of correct application of aesthetic concepts may vary from person to person, or from time to time.

\section{Three puzzling phenomena}

The view outlined, that aesthetic concepts and judgements are judgedependent, even though it can be motivated and supported in the way indicated, also faces some apparently disconfirming phenomena, i.e. phenomena that seem to conflict with what the view predicts. Some of these phenomena are quite well-known and need to be addressed. I shall here distinguish three such phenomena, two of them broadly taken from Hume, and one taken from Kant.

The view that aesthetic judgements are judge-dependent shares some key features with Hume's sentimentalism, in that the correctness of such a judgement will depend on the response-profile a judge happens to have. 
Hume mentions two problems for this sort of view, in the form of tensions between the view and the way we commonly treat aesthetic matters.

First, if aesthetic judgements are governed by norms of correctness as specified in (JD), we should expect that no aesthetic judgement should be incorrect or wrong in itself, i.e. just in virtue of its content: if the judge has the appropriate dispositions, then an aesthetic judgement with any (contingent) content could be correct for that judge. ${ }^{10}$ However, it seems as if we can easily come up with examples of aesthetic judgements that are, in Hume's words, "absurd and ridiculous" (Hume 1757, §9). One of Hume's examples is the judgement that there is "an equality of genius and elegance between Ogilvy and Milton" (Hume 1757, §9). The problem for Hume as well as for the proponent of the judge-dependence of aesthetic concepts is that for people with the right sentiments or dispositions, i.e. a disposition to favour Ogilvy in the relevant way, it should be correct to judge in this way. So there should not be contents of aesthetic judgement that automatically count as absurd or ridiculous.

The second problem is not specifically raised by Hume as a problem for his own sentimentalism, but much of his discussion in "Of the Standard of Taste" can be seen as an attempt to resolve this problem for his view. This second problem consists in the apparent existence of expertise in aesthetic matters, in other words the apparent existence of thinkers with a superior faculty of judgement concerning aesthetic matters. Again, if aesthetic judgements are Humean sentiments rather than judgements of the understanding, then it is not clear why anyone should qualify as an expert on aesthetic matters. The same goes for the view that aesthetic judgements are judgedependent, as outlined in the last section: if the correctness of an aesthetic judgement depends on the judge's profile of dispositions to respond to objects of aesthetic appraisal, and if judges tend to differ significantly in their response profiles, then why should we elevate some judges with the predicate of "aesthetic expert," i.e. as someone superior in their ability to judge

10 Another question would be whether the dispositions required for the correctness of the judgement are normal or admirable. But that is independent of the correctness of the judgement, if it is judge-dependent in the way outlined. I will come back to evaluations of the response dispositions of judges below. 
on aesthetic matters, someone on whom we can rely independently of our own experiences, and perhaps even against our own experiences.

A third puzzling phenomenon can be found in Kant's Critique of Judgement. Kant claims, not implausibly, that aesthetic judgements involve a certain claim to "universal validity." He says that

when [someone] puts a thing on a pedestal and calls it beautiful, he demands the same delight from others. [...] he demands this agreement of them. He blames them if they judge differently. (Kant 1790, 52)

This, too, suggests that aesthetic concepts can't be judge-dependent in the way I have been suggesting. For if the correctness of an aesthetic judgement with a certain content depended on features of a judge that he may not share with other judges, then it would seem unreasonable to expect or even demand of others that they judge in line with one's own judgement. Others may not have the same, or relevantly similar, response profiles and therefore a content that it is correct for me to accept may not be for others. So the claim to universal validity that Kant thinks we are making would seem to be quite confused.

To sum up, then, the three puzzling phenomena to be discussed are the following. First, we regard aesthetic judgements with certain contents as mistakes independently of the judge's experiential responses (e.g. "Ogilvy is better than Milton"). Secondly, some people seem to enjoy the status of experts in matters aesthetic. And finally, we seem to be making a claim to universal validity when making aesthetic claims.

\section{Three ways of being a good aesthetic judge}

In order to show how these phenomena can be explained (or explained away), let me begin by distinguishing two factors on which the correctness of an aesthetic judgement depends according to the thesis of judge dependence. Recall the schematic thesis of judge-dependence:

(JD) For all subjects $s$ and all objects $o$ : it is correct for $s$ to apply $\mathrm{C}$ to $o$ if and only if $s$ is disposed to have experiential response $\mathrm{R}$ to $o$ under favourable conditions. 
I claimed that aesthetic concepts are judge-dependent in the sense of being governed by instances of (JD) where the response R is some form of aesthetic appreciation (a kind of pleasure or displeasure), and moreover, that dispositions to response $\mathrm{R}$ can vary from judge to judge (and possibly from time to time). This means that the correctness of applying an aesthetic concept to a given object depends on two factors being aligned with one another: (a) the relevant (response-causing) features of the object and (b) the judge's dispositions to respond (at the time of applying the concept), i.e. the judge's response-profile. If the object has features that would elicit the required response in the judge under favourable conditions, then the concept was correctly applied.

There are different methods for ensuring that one apply aesthetic concepts correctly, in line with (JD). In general, if one wants to find out whether an object has a certain disposition, i.e. would respond in a certain way under certain circumstances, one can put the object into (approximately) such circumstances, and see whether it responds in that way. Thus, to use a paradigmatic example of a disposition: to see whether a vase is fragile, I can drop it onto a hard surface and see whether it breaks. So, what I want to call the "canonical method" of arriving at an aesthetic judgement involves attempting to provoke the relevant response in oneself by exposing oneself to the object under approximately favourable conditions (cf. Lewis 1989). Thus, if I look at the painting in good lighting conditions when I myself am also in a favourable state (e.g. I am wearing my glasses, if needed, I am awake, not intoxicated, not impaired by distractions or prejudices, etc), then I can assess in a direct way whether I am experiencing the required response. In fact, I do not even need to become aware of my response and then infer that the concept can/cannot be correctly applied. Rather, judges will often use the canonical method in an "unreflective" way, merely coming to apply the concept reliably in line with the experience the object elicited in them, without any explicit thought about their own experiential response.

But there may also be non-canonical, more indirect methods. In general, in order to find out whether an object has a disposition to react in a certain way under certain conditions, one does not need to put the object into (approximately) those conditions. One can also apply general knowledge 
about objects of this type to make an inferentially justified judgement. For example, one does not need to attempt to break a vase in order to find out whether it is fragile. Instead one can judge the vase to be fragile for example on the basis of a belief that it is made of porcellain or glass etc, and the general belief that vases made from these materials are fragile. Similarly, there are indirect ways to find out about those features of objects of aesthetic appraisal that are responsible for their affecting aesthetic judges in the way they do (see (a) above). To use a simple example, perhaps drinking coffee made from a certain type of blend of coffee beans, using a certain method of coffee-making, tends to cause gustatory pleasure in me in favourable conditions. So, I can rationally judge a particular cup of coffee to be delicious merely on the basis of my view that it was prepared in this way from this type of blend. Or perhaps paintings by a certain artist generally tend to cause a response of the right kind of disinterested pleasure in me. So I might judge that a particular painting is beautiful merely on the basis of my view that it was made by this artist, without having seen the painting. ${ }^{11}$

Now, this general picture of how the application of aesthetic concepts can be justified, i.e. how thinkers can ensure they judge correctly, leaves room for a variety of ways in which one can assess the competence of aesthetic judges, and corresponding ways in which one aesthetic judge can be superior to another. To begin with, we can measure the likelihood to which a judge's aesthetic judgements are correct, i.e. the likelihood that the judge will apply an aesthetic concept only to those objects which would elicit the appropriate response in him under favourable conditions. We can also make corresponding comparisons: one judge may be more likely than another to apply an aesthetic concept only to things that would in fact provoke the

11 There is a certain tradition in Aesthetics, following e.g. Wollheim (1980, 156) that denies the legitimacy and possibility of what I have called "non-canonical methods" in the realm of properly aesthetic judgement, or perhaps denies that the resulting judgements are genuine applications of aesthetic concepts. I will here assume without argument that this view is wrong. To the small extent to which my explanation of phenomenon P2 below depends on this assumption, my conclusions are merely conditional. See, e.g., Wollheim (1980); Hopkins (2001); Budd (2003); Franzén (2018) or Dinges and Zakkou (2020) for discussion. 
right response in him or herself under favourable conditions. Let us call this way of assessing the reliability of a judge "likelihood of correct judgement."

This is an important dimension of assessment, however it does not by itself explain all aspects of our practice of treating some people as experts. Experts are people we can rely upon, but those who are likely to judge correctly need not therefore be people whose judgements we can simply rely upon. More precisely, we cannot just accept the contents they accept and thereby be likely to judge correctly ourselves. Such a conclusion would require some further assumption, for example that the reliably correct judge has dispositions to respond that are relevantly similar to our own.

However, the general picture allows us to distinguish further dimensions of assessing aesthetic judges. We can also assess the abilities of a judge to discern those features of objects of aesthetic appraisal that underlie our experiential response to them. For example, whether a given taster experiences gustatory pleasure upon tasting a dish causally depends on many overlapping factors, such as the composition of the food, the ingredients, their origin, their composition, the way the meal was prepared, by whom, using which tools and procedures, etc. Similarly, the response an aesthetic appraiser experiences when seeing a painting under favourable conditions causally depends on many underlying features of the painting, such as the distribution and structure of the paint on its surface, the composition of the painting, the painter who made it, the period in which it was made, the school of painting to which it belongs, etc. Independently of whether a judge is good at applying an aesthetic concept correctly, i.e. only to those things which elicit the relevant response in him or herself, a judge can be more or less reliable at recognizing and discerning these underlying factors. For example, a culinary expert may be very knowledgeable about various types of raw ingredients, their provenance and resulting qualities, the possibilities of using these ingredients, techniques for doing so and the resulting flavours, and she might combine this knowledge with the ability to detect all these features gustatorily, etc. An expert on paintings may be a superior judge on the provenance of paintings, on their paint distribution and the resulting experiential effects, on painters and their characteristic techniques and resulting experiential effects, on the cultural context (their own and the painter's) and its effect on the responses provoked by the painting etc. 
If we introduce the umbrella term "underlying features" for all the causal factors (including extrinsic, contextual factors) that are responsible for judges' experiential responses to objects of aesthetic appraisal, then we can say that some thinkers are excellent aesthetic judges in the sense that they have excellent abilities to discern and recognize underlying features. The knowledge of, and ability to discriminate, underlying features can be subdivided into many different types of such knowledge and abilities. There is general knowledge (e.g. paintings from this period are generally produced with such and such technique) and particular knowledge (e.g. this painting exhibits a composition typical of such and such period). There are also recognitional skills (such as the skill to recognize a type of composition by looking at a painting) and recognitional skills can be based on powers of discrimination with varying degrees of fineness (one judge may be able to discern differences that another judge is not able to notice). All the recognitional skills can be orthogonally divided into those that are based on direct experience of the objects of aesthetic appraisal (as in a direct visual appreciation of a painting, or sampling of a food), and those that are based on indirect kinds of evidence (e.g. via general knowledge, via measurement devices, etc). There is, finally, the associated skill of being able to exercise the above skills and the above knowledge reliably in the face of sources of distraction, such as prejudice, comparative environment, social pressure etc. Thus, the knowledge of, and abilities to discern, underlying features encompasses a very wide range of competence. Let me refer to them all summarily as "competence concerning underlying features."

Excellent competences concerning underlying features may or may not be accompanied by the tendency to apply aesthetic concepts correctly (i.e. in line with one's own dispositions to respond), even if, presumably, there will be many correlations. However, a judge with superior competences concerning underlying features will be a valuable source of information to others. It is quite obvious how such a judge's general and particular knowledge of underlying features can be useful when articulated in non-aesthetic (i.e. non-judge-dependent) terms, for example by saying "Painter $\mathrm{X}$ tends to use technique Y." But even if such a judge's discernments of underlying features are articulated in judge-dependent terms (e.g. "Painter X paints better still lifes than painter Y."), an audience who is less competent concerning 
underlying features may nevertheless rely on the superior judge's detection of a relevant difference.

I have distinguished two dimensions of assessing aesthetic judges: likelihood of correctness and competences concerning underlying features. Both these types of assessment are arguably objective: it does not depend on one's aesthetic standard or one's taste whether one can correctly regard a judge as more or less likely to be correct, better or worse at telling apart underlying features. ${ }^{12}$ The third type of assessment that I want to distinguish differs in this respect. I am speaking about an evaluative assessment of a judge's response profile itself, i.e. their dispositions to respond to objects of aesthetic appraisal. For example, one might regard a disposition to respond more favourably to Hip Hop than to Heavy Metal as an inferior response profile. Another might regard a taste that evaluates either of the two positively as as a bad standard of taste. These evaluations of the response profiles, or tastes, of judges seem themselves to depend on evaluative standards. However, the point of distinguishing this third type of assessment does not depend on this. The important point is rather that an evaluation of a judge's response profile, i.e. his or her taste, is independent of an evaluation of that judge's likelihood of correctness and that judge's competences concerning underlying features. For example, one might recognise someone as excellent in the latter two respects while regarding their taste as inferior.

Whether or not evaluations of response profiles are an objective matter, they do not affect the conceptual competence of judges. According to the thesis of judge-dependence, correct application of the concept requires that one's judgements are in line with one's dispositions to respond. But this does not require any particular type of disposition to respond. A judge could have any response profile whatsoever and still be a fully competent user of aesthetic concepts. If we regard one response profile as superior to another that is not an evaluation of a judge's competence as a concept user, or of his or her likelihood of using these concepts correctly.

Humean sentiments are spontaneous and beyond rational control. So, in Humean terms, a judge's response profile, their dispositions to respond to

12 Except perhaps because likelihood assessments are judge dependent, as claimed by subjectivists about probability, e.g. Keynesians or Bayesians. 
objects of aesthetic appraisal, is something beyond direct voluntary or rational control. At best, I can deliberately undergo a training programme that will gradually alter my dispositions. Just as I cannot directly control the phenomenal quality of my visual experiences when looking at certain objects, I cannot directly control my aesthetic responses to objects of aesthetic appraisal.

Perhaps this hard Humean line needs to be softened somewhat when we are talking about more refined aesthetic responses. These may be more susceptible to cognitive influences than, for example, the brute phenomenal responses involved in sensory perception. One might argue, for example, that a thinker's dispositions to respond to a work of art may change if they are told that it was made with a certain technique, or even that it is merely a very good copy of the original. We may reply that this is because the technique (and the status as original) is one of the underlying features that are causally responsible for the characteristic experiential response. Of course, to the extent to which we admit such influences, we are construing the "experiential" response as more "intellectual." If we assume such cognitive influences, i.e. that a judge's response profile is not merely a Humean sentiment beyond all rational control, we may be able to construe our evaluations of judges' response profiles partly in terms of their level of informedness.

However, even with this concession of a limited rational evaluability of response profiles (as more or less informed), the comparative evaluation of response profiles remains independent of an evaluation of judges' likelihood of correctness or their competences concerning underlying features.

Before moving on, it is worth pointing out the importance most of us attach to comparing the response profiles of different judges, i.e. their taste. People's aesthetic responses seem to be associated with certain social groups, and members of such groups may construe their own "identity" partly in terms of their taste. For example, some seem to regard a taste that favours paintings by Jack Vettriano as vulgar, while others regard those as snobbish who do not appreciate Vettriano's art.

To sum up: we can distinguish three ways of assessing aesthetic judges: (a) likelihood of judging correctly; (b) competences concerning underlying features; and (c) the quality of the response profile (which may itself be 
a judge dependent issue). Despite some correlations between the three, they are independent of one another.

\section{The puzzles addressed}

Let me briefly recapitulate the three puzzling phenomena that threaten the response-dependence account, before I begin addressing them:

P1 Aesthetic judgements with certain contents just seem wrong ("absurd and ridiculous"): we regard them as mistakes no matter what the personal features of the judge may be.

P2 There seem to be experts regarding aesthetic questions (wine experts, art critics, etc).

P3 When making aesthetic claims or judgements, we seem to be making some kind of claim to universal validity (expecting and demanding of others that they judge likewise).

How can phenomenon P1 be explained, i.e. the fact that aesthetic judgements with certain contents seem mistaken for any judge? Hume's example is the judgement that Ogilvy is equal in elegance and genius to Milton. What would be a contemporary example? The judgement that Conan the Barbarian is equal to Ulysses perhaps? The sphere of gustatory taste might provide better examples: the judgement that rotten eggs are delicious seems to be a mistake for any judge. Or perhaps the judgement that Florence is an ugly city can serve as another example.

It seems to me that such examples may seem to be convincing for at least two different types of reason. On the one hand, they are judgements that it would be correct to make only for a judge with a response profile that we would evaluate negatively. Thus, we may think that any response profile which yields a negative aesthetic response to Florence, or a gustatory response of delight to rotten eggs, must be a sick or perverted response profile. If this is the source of the impression that such judgements are mistaken independently of who the judge is, then the judge dependence account can clearly cope: the basis of the assessment as mistaken is a negative assessment of reponse profiles of a certain type (namely those relative 
to which the judgement would be correct). Perhaps no normal human, for biological reasons, will respond with gustatory delight to rotten eggs (although I believe there may be exceptions). Perhaps any aesthetic standard that rates Florence as ugly (or that equates the quality of Conan the Barbarian with Ulysses) must be condemned as perverted. If so, this would explain the view that such judgements are always mistaken: either the judgement is not in line with the response profile, or the response profile itself is a mistake: it is not a set of dispositions one should have. This explains why some may have the impression that there must be a mistake in regarding Milton and Ogilvy as equal, whatever the dispositions of the judge are. Once we concede their negative evaluation of any standard of taste that would treat Ogilvy and Milton as equal, the impression is correct: either a judge has an ok response profile, in which case he judged incorrectly (in the sense of not judging in line with the norms spelled out in the relevant instance of (JD)). Or she has a response profile that it is a mistake to have, in which case, perhaps, she may be judging in line with the norms of (JD), but is guilty of having the wrong response profile. So, the impression that judgements with such a content are a mistake to make, whoever the judge may be, is correct.

It is important to stress, however, that this take on P1 still leaves open that some judges might have the condemned response profiles, so that they would be applying the relevant aesthetic concepts correctly if they made these judgements. Thus, perhaps a judge with a strong aversion to terracotta and marble in a city would be judging correctly if judging Florence to be ugly. Fungus the Bogeyman will correctly judge rotten eggs to be delicious because they produce in him the required gustatory delight. Thus, our negative evaluations of the response profiles that would make such judgements correct do not show that these judgements cannot be made correctly in the sense of being made in line with the conceptual norms articulated in the relevant instance of (JD).

Let us move on to P2: some thinkers undoubtedly enjoy the status of aesthetic experts, as do for example wine experts or art critics. Does the judge dependence account outlined leave room for this to be a deserved status? I believe it does, though we ought to be careful to distinguish the various dimensions of assessment of aesthetic judges that I distinguished. 
The status of expert can be warranted on the basis of superior competence concerning underlying features (which in turn can take many forms). But it can also be warranted to treat someone as expert because they have a type of taste (i.e. response profile) that one regards as superior and worth emulating. Superiority in terms of greater likelihood of correctness, however, can play only an indirect role in justifying expert status. Let us look at some examples.

Wine experts are usually superior to others in their competences concerning underlying features, and this is usually all that matters in this case. This superiority, as mentioned, can take many different forms, from superior abilities to discriminate flavours in canonical ways to superior general knowledge of wines (usually restricted to certain regions). Often, a judge with superior wine-tasting abilities will also have a more differentiated response-profile. But I presume that the expert status is in these cases owed usually to their competences concerning underlying features. They might also be good sources of advice because they have general knowledge of what others' palates are like.

By contrast, expert art critics, I suspect, typically acquire their status due to a combination of enhanced competences concerning underlying features (both in their discriminatory skills and in their general and applied knowledge) and due to a response profile, i.e. a taste in art, that is regarded as superior - at least by those who regard them as experts. Thus, art critics will often be more perceptive or more knowledgeable than others, but they might also be admired for their taste. To the extent to which their response profile is emulated and admired, their role of expert is similar to that of a guru: they serve as a model for others, who would like to be like them.

Likelihood of correctness will only play an indirect role when it comes to the expert status: if one thinker believes that she has a response profile similar to that of another person, who in turn has a high probability of being correct in her aesthetic judgements, then relying on their expert judgement seems to offer a quick shortcut to achieving their rate of correctness without needing any competence concerning underlying features. Thus, the usefulness of one thinker's correctness to another thinker, who wants to rely on the first's testimony, depends on the assumption that the response profiles or tastes are relevantly similar. There are, of course, further 
assumptions that would allow one to draw inferences from the fact that someone with a high probability of correctness has made a certain aesthetic judgement: e.g. explicit assumptions about the thinker's response profile. But these are not a basis for an explanation of the status of aesthetic expert in the sense of P2.

Phenomenon P2, then, can be explained within the judge-dependence framework: when we regard certain judges as experts in aesthetic matters, we regard them either as especially competent concerning underlying features, or we value their taste (their set of dispositions to respond to objects of aesthetic appraisal) as worth emulating, or both.

This leaves us with phenomenon P3, the universality that Kant claims to pertain to aesthetic judgements. Does the judge dependence of aesthetic concepts make room for this claim to universal validity? I will argue that there is no room for the phenomenon exactly as stated by Kant. However, the judge-dependence account offers a ready way to explain some nearby claims that may well be the basis for thinking (erroneously) that Kant's strict universality claim is correct. This will again make use of the idea that we can assess judges in the three ways I outlined in §3.

One straightforward way in which certain aesthetic judgements might come with a claim to universal validity would concern the negations of the judgements that figured in phenomenon P1. The judgement that Florence is not ugly, or that rotten eggs are not delicious, are plausibly taken to be correct for any judge, simply because no-one is likely to have a response profile relative to which these are not correct. However, this will not do justice to the phenomenon as it was intended by Kant: the idea of P3 is that we expect and demand others to judge as we do not only in these special cases, that actually command widespread agreement, but that we expect and demand this whenever we make aesthetic judgements.

A more adequate explanation might be given in terms of our evaluations of tastes (response profiles). Even if it is largely an involuntary matter which response profiles we have, we do nevertheless attach great social significance to them. We regard people as admirable or despicable, as suitable friends or bad company, merely on the basis of their taste. We identify ourselves strongly with our own taste and regard it as an essential feature that defines who we are, and which socially significant groups we belong to. 
As a result, we will regard people who change their taste too quickly, or for no good reason, as inauthentic. This sheer level of significance can explain, to some extent, why it seems that we expect and demand that others judge aesthetically as we do: on the one hand, we expect and demand them to assess the underlying features as we do. But on the other hand, we also have a strong social expectation that they have a taste similar to ours, so that if they meet the expectation, and they judge as we do, then their judgements will be correct just if ours are.

One limitation of this explanation is that it does not really account for us having this expectation, or making this demand, completely universally on everyone. Rather, the account predicts that we should not have these expectations and demands whenever we expect others-perhaps members of a different group - to have quite different tastes. So, this explanation requires us to treat $\mathrm{P} 3$ as involving an exaggeration.

A third way to try to do justice to P3 takes seriously the idea that the phenomenon concerns the explicit claims we make rather than concerning (potentially unexpressed) judgements. As Kant says, "when [someone] puts a thing on a pedestal and calls it beautiful, he demands the same delight from others. [...] he demands this agreement of them." When we assert a proposition, we are proposing to our conversational partners to accept this proposition for the purposes of the conversation. They can veto the proposal, by denying what we said, but if they let it pass, then the proposal becomes accepted, the proposition accepted for the purposes of the conversation. Many models of conversation acknowledge this basic picture (Stalnaker 1978, 2002; Lewis 1979b; Brandom 1983) The picture is controversial for perspectival or centered propositions (see e.g. Torre 2010; Ninan 2010a, 2010b; Stalnaker 2014; Kindermann 2018), but can be defended for that case (Kölbel 2013; Dinges 2017). If we accept the basic picture of the conversational effect of an assertion, we have the beginning of an explanation of phenomenon P3: we are making a demand on anyone who might be or become a party to this conversation that they accept, at least for the purposes of the conversation, what we have asserted. This is a demand they may not comply with, i.e. they may deny what we have asserted, thereby preventing the asserted proposition from becoming mutually accepted. 
Now, it is important here to contrast aesthetic predicates, such as "beautiful" with predicates that wear their judge-dependence on their sleeve, such as "is my favourite painting." When I call a painting "beautiful," I may expect and demand the agreement of others in the sense of expecting and demanding that they allow this to become accepted in our conversation. This will not be so when I call a painting "my favourite painting": even though the concept of one's favourite painting may well be judge-dependent too, this particular form of words would not bring about acceptance of the painting in question as one's favourite painting in the conversation, even if no-one objects. When judge-dependent concepts are expressed through indexical language, the conversational effect will be different: at best it will become accepted that the painting is the favourite painting of that participant who just called the painting her favourite painting. ${ }^{13}$

I conclude that while phenomenon P3 cannot perhaps be saved exactly as stated by Kant, we can at least "explain it away": the account predicts some phenomena that are similar to P3 and may well have been the basis for the attraction of Kant's universality claim. The defender of judge-dependence needs to deny that an aesthetic judge who is minimally informed about the occurrence of interpersonal differences in taste can reasonably expect and demand of everyone unrestrictedly that they agree (in this sense, P3 is denied). But they can accept that we expect and demand of anyone whose taste we are presuming to share, that they agree with our judgements as to which things are beautiful. They can also accept that everyone who asserts that something is beautiful ("calls it beautiful") thereby makes a proposal to accept for the purposes of the conversation, that that thing is beautiful, and thereby expect and demand that their conversational partners do accept this by not rejecting the assertion they have made.

\section{A parallel case for the judge dependence of moral judgement?}

In this final section, I want to argue for a certain asymmetry between moral and aesthetic judgement. While some of the motivations for a judge-

13 See Kölbel (2013) for elaboration. 
dependence account transfer straightforwardly from the aesthetic to the moral case, there is also evidence against the judge-dependence of moral concepts. In my view, this evidence forces us to draw one of two uncomfortable conclusions: either that moral concepts are incoherent, or that the users of moral concepts are persistently confused about these concepts.

I take it that aesthetic concepts (at least the ones that I have been discussing here - not all aesthetic concepts mentioned by Sibley in his famous 1959 article) are a species of evaluative concept. Another species is that of moral concepts. However, some evaluative concepts seem not to be specifically related to any narrowly experiential response. Moral or normative concepts may impose restrictions on the preference structure of judges without being associated with any specific sensory response. However, we already saw in the case of aesthetic concepts that it is possible to conceive of the response mentioned in instances of (JD) as experiential in a wide sense. Aesthetic appreciation may be a partly intellectual response. Similarly, the responses associated with moral concepts - if treated on the (JD) modelmay include experiential responses more or less closely tied to perception or other basic responses. Perhaps they are quasi-sensory experiences produced by a quasi-sensory "moral sensibility." For simplicity, let us call the relevant responses in the moral case "moral approval" and "moral disapproval."

We might then propose various instances of (JD) as articulations of the norms governing various moral concepts:

(G) For all subjects $s$ and all objects $o$ : it is correct for $s$ to apply good to $o$ iff $s$ is disposed, under favourable conditions, to respond with moral approval to $o$.

(B) For all subjects $s$ and all objects $o$ : it is correct for $s$ to apply bad to $o$ iff $s$ is disposed, under favourable conditions, to respond with moral disapproval to $o$.

(O) For all subjects $s$ and all objects $o$ : it is correct for $s$ to apply ought to action type $a$ iff $s$ is disposed, under favourable conditions, to respond with moral disapproval to a failure to perform $a$.

One advantage of this type of approach is that it offers a clear explanation of the motivational nature of these evaluative concepts. Motivational internalism in metaethics has remained controversial, but there seems to be 
at least a very convincing suggestion that competence with evaluative concepts requires having a corresponding motive when applying them. Those who claim not to have the motive while also claiming to be applying the concept (so the internalist claims) have not really understood the concept or are applying a related but different concept (i.e. an "inverted commas use"). A judge-dependence account has no difficulty explaining this whenever the response mentioned in the relevant instance of schema (JD) is an experience that is appropriately motivating. If pleasure is intrinsically desirable, and correct application of the concept of beauty requires of the judge that he or she be disposed to experience a certain kind of pleasure in response to that object, then judging an object to be beautiful will have immediate consequences for rational motivation. If such a judgement does not, ceteris paribus, motivate me to choose the object over others not judged to be beautiful, then something will have gone wrong: be it my competence with the concept of beauty or my processes of rational deliberation. The same goes for the proposed instances of (JD) for moral concepts: if moral approval or disapproval is a response associated with the application of moral concepts, then this explains the link between the genuine application of moral concepts and motivation. It is rational to prefer, ceteris paribus, good things to those that are not. Why? - because it is rational to prefer ceteris paribus what one approves of.

The second type of support for a judge-dependence account of aesthetic concepts came from the observation that we regard it as a requirement for competence that users of these concepts apply them in line with their dispositions to respond. In the moral case, analogous observations support an analogous conclusion: we tend to require that competent users of moral concepts apply these concepts in line with their own responses of moral approval or disapproval. It is hard to imagine a case where we classify a thinker as competent with moral concepts on the basis of their applying them to the right range of objects, but criticize them for morally approving or disapproving out of line with their moral judgements. Perhaps this observation is just as controversial as the purported observations supporting internalism. But let that pass. My aim here is to point out an asymmetry and difficulty that would arise for a judge-dependence account of moral concepts even if we accept this evidence. 
The asymmetry shows up when we consider a piece of evidence that can be adduced to support the view that aesthetic concepts are judge dependent in addition to being response dependent, i.e. that the relevant response profiles can vary from judge to judge. This is supported by the fact that we have no difficulty in conceding that someone else is correctly applying the concept of beauty, say, to a given case, yet refuse to apply the concept ourselves, since it would not be correct for us. Thus, it seems coherent for me to concede that someone else is complying with all the conceptual norms when calling something beautiful, yet to deny that that thing is beautiful, since this is what the conceptual norms require of me. ${ }^{14}$

In the moral case, by contrast, there seems to be something very odd about conceding that someone else is applying a moral concept correctly, yet to refuse to apply it oneself. Thus, even if the instances of (JD) proposed above were correct, there seems to be an additional requirement, on pain of incompetence, that different thinkers morally approve and disapprove alike.

A similar asymmetry affects the reasons that can be adduced against an ideal judge account of aesthetic concepts on the model of (IJ) above in $§ 2$. If aesthetic concepts followed the (IJ) model, then persistent divergence from applying these concepts in line with an ideal judge would count as a manifestation of incompetence. However, as long as these uses of a concept are plausibly in line with the user's own aesthetic responses, we draw no such conclusion. Thus, the (IJ) model seems to be the wrong model in the case of aesthetic concepts. The parallel case, however, cannot be made for moral concepts: if a thinker applies moral concepts perfectly in line with their own sentiments of moral approval or disapproval, but they diverge sharply from the way we think an ideal moral judge would apply the concepts, then we might conclude that the thinker is not competent with the moral concepts - at least we are more likely to do so than in the aesthetic case. The conceptual requirements seem to include both that the thinker judge in line with their own responses of approval and disapproval, and also that they judge in line with the responses they would have if they were ideal judges.

14 NB: this feature is directly related to the restrictions the judge dependence account is subject to in connection with phenomenon P3 above. 
Thus, in the moral case there seems to be more pressure than in the aesthetic case to say that correctly performing judges will judge alike. If we wanted to follow the approach taken in $(\mathrm{G}),(\mathrm{B})$ and $(\mathrm{O})$, i.e. accept that these articulate correct conceptual norms for the concepts of good, bad, and ought, then I can see only two fairly undesirable options: either we class the extra requirement of agreement amongst correctly performing judges as conceptual, or we don't. On the first option, moral concepts are deficient, on the second option the concept users are.

On the first option, the above instances of (JD) are not the only norms governing moral concepts. In addition, there are requirements that resemble instances of (IJ): concept users are required to judge in line with the approval and disapproval patterns of an ideal judge. But these conceptual requirements impose inconsistent requirements to the extent to which concept users diverge in their approval responses from ideal judges. In an exceptional world, in which moral education is perfectly uniform as well as perfectly successful, the two norms may be consistent. But not in any other case.

The effect of incoherent conceptual requirements may not always be detrimental. Some argue that vague concepts are governed by an ultimately incoherent tolerance principle (a principle that is both analytic and false, argues Eklund 2002). Some argue that compliance with the equivalence schema is part of the conceptual requirements on the concept of truth, yet when we discover the liar paradox, we will refrain from accepting the requirement in certain cases (Horwich 1998). Nevertheless, they claim, we are using these concepts fruitfully by exercising caution with the problematic principles: we simply refuse to apply the principles in problematic cases. Perhaps in the moral case it is harder to brush the incoherence under the carpet: both $(\mathrm{G})$ and an appropriate (IJ) requirement would seem to be quite central demands. Thus perhaps in this case the inconsistency in the conceptual rules can be seen as driving us towards reaching a situation where the rules do not conflict, i.e. a case where our approval patterns are those of an ideal judge.

On the second option, the extra requirement of agreement amongst correctly performing judges is not construed as conceptual, and (G), (B) and (O) are the sole conceptual norms governing these moral concepts. On this view, our reluctance to say "He/she is applying the concept correctly to this object, but it would not be correct for me to apply it." is a reflection not 
just of conceptual norms, but also of certain non-conceptual requirements. Correctness in applying the concept encompasses two components, only one of which is conceptual. The conceptual part requires the thinker to judge in line with $(\mathrm{G}),(\mathrm{B})$ or $(\mathrm{O})$. However, full correctness also requires them to have the approval patterns of an ideal judge. If this is not the case, the application is not fully correct.

The disadvantage of this option is that there seems to be no evidence in the behaviour of concept users that would support the view that some of the norms they bring to bear regularly, and which seem to be an integral part of educating others in the use of moral concepts, are not in fact conceptual.

I conclude that a judge dependence account of moral concepts, while sharing some of the advantages of a judge-dependence account of aesthetic concepts, also suffers from difficulties not faced by the aesthetic analogue. However, it is not clear that any better account is available on which neither our moral concepts nor our patterns of use are deficient.

\section{Acknowledgments}

This paper originates from a paper delivered at the conference Realism and AntiRealism in Aesthetics and Metaethics at the University of Cambridge in 2014. I thank the participants for their comments, and the organizers, Louise Hanson and Daan Evers, for inviting me. Thanks also to Filippo Contesi for comments on an earlier draft. I would also like to thank two referees for this journal for their helpful comments.

\section{Funding}

The research leading to this article benefitted from MINECO, Spanish Government, I+D+i programme, grant FFI2012-37658 and also CONSOLIDER INGENIO Programme, grant CSD2009-0056, which is hereby gratefully acknowledged.

\section{References}

Brandom, Robert. 1983. "Asserting." Nô̂s 17 (4): 637-50.

https://doi.org/10.2307/2215086

Budd, Malcolm. 2003. "The Acquaintance Principle." British Journal of Aesthetics

43 (4): 386-92. https://doi.org/10.1093/bjaesthetics/43.4.386 
Dinges, Alexander. 2017. "Relativism and Assertion." Australasian Journal of Philosophy 95 (4): 730-40. https://doi.org/10.1080/00048402.2017.1284248

Dinges, Alexander and Julia Zakkou. 2020. "Taste, Traits and Tendencies." Philosophical Studies, online first. https://doi.org/10.1007/s11098-020-01470-7

Egan, Andy. 2007. "Epistemic Modals, Relativism and Assertion." Philosophical Studies 133 (1): 1-22. https://doi.org/10.1007/s11098-006-9003-x

Egan, Andy. 2012. "Relativist Dispositionalist Theories of Value." Southern Journal of Philosophy 50 (4): 557-82. https://doi.org/10.1111/j.2041-6962.2012.00136.x

Eklund, Matti. 2002. "Inconsistent Languages." Philosophy and Phenomenological Research 64 (2): 251-75. https://doi.org/10.1111/j.1933-1592.2002.tb00001.x

Franzén, Nils. 2018. "Aesthetic Evaluation and First-Hand Experience." Australasian Journal of Philosophy 96 (4): 669-82. https://doi.org/10.1080/00048402.2018.1425729

Hopkins, Robert. 2001. "Kant, Quasi-realism, and the Autonomy of Aesthetic Judgement." European Journal of Philosophy 9 (2): 166-89. https://doi.org/10.1111/1468-0378.00134

Horwich, Paul. 1998. Truth. Oxford: Oxford University Press. https://doi.org/10.1093/0198752237.001.0001

Hume, David. 1757. "Of the Standard of Taste." In Four Dissertations. London: A. Millar.

Kant, Immanuel. 1790. Critique of Judgment. Page reference to trans. Meredith. Oxford: Oxford University Press 1928.

Kindermann, Dirk. 2018. "Varieties of Centering and De Se Communication." In De Se Thought and Communication, edited by Manuel García-Carpintero and Stephan Torre, 307-39. Oxford: Oxford University Press. https://doi.org/10.1093/acprof:oso/9780198713265.003.0012

Kölbel, Max. 2013. "The Conversational Role of Centered Contents." Inquiry 56 (2/3): 97-121. https://doi.org/10.1080/0020174X.2013.784456

Kölbel, Max. 2014. "Agreement and Communication." Erkenntnis 79 (1): 101-20. https://doi.org/10.1007/s10670-013-9447-2

Kölbel, Max. 2015. "Relativism 1: Representational Content." Philosophy Compass 10 (1): 38-51. https://doi.org/10.1111/phc3.12190

Lewis, David. 1979a. "Attitudes De Dicto and De Se." Philosophical Review 88 (4): 513-43. https://doi.org/10.2307/2184843

Lewis, David. 1979b. "Scorekeeping in a Language Game." Journal of Philosophical Logic 8 (1): 339-59, reprinted in his Philosophical Papers, vol. 1, Oxford: Oxford University Press, 1983. https://www.jstor.org/stable/30227173

Lewis, David. 1989. "Dispositional Theories of Value." Proceedings of the Aristotelian Society Supplementary Volume 63 (1): 113-37. https://doi.org/10.1093/aristoteliansupp/63.1.89 
Ninan, Dilip. 2010a. "Semantics and the Objects of Assertion." Linguistics and Philosophy 33 (5): 355-80. https://doi.org/10.1007/s10988-011-9084-7

Ninan, Dilip. 2010b. "De Se Attitudes: Ascription and Communication." Philosophy Compass 5 (7): 551-67. https://doi.org/10.1111/j.1747-9991.2010.00290.x

Sibley, Frank. 1959. "Aesthetic Concepts." Philosophical Review 68 (4): 421-50. https://doi.org/10.2307/2182490

Stalnaker, Robert. 1978. "Assertion." In Syntax and Semantics 9: Pragmatics, edited by P. Cole, 315-22.

Stalnaker, Robert. 2002. "Common Ground." Linguistics and Philosophy 25 (5/6): 701-21. https://doi.org/10.1023/A:1020867916902

Stalnaker, Robert. 2014. Context. Oxford: Oxford University Press.

Torre, Stephan. 2010. "Centered Assertion." Philosophical Studies 150 (1): 97-114. https://doi.org/10.1007/s11098-009-9399-1

Wollheim, Richard. 1980. "Art and Evaluation." In Richard Wollheim, Art and Its Objects: Second Edition with six supplementary essays, 152-61. Cambridge: Cambridge University Press.

Wright, Crispin. 1992. Truth and Objectivity. Cambridge, Mass.: Harvard University Press. 